\title{
EFFECT OF NUMBER OF LOADING CYCLES ON DYNAMIC CHARACTERISTICS OF REINFORCED CONCRETE BRIDGE PIER COLUMNS
}

\author{
By Kazuhiko KAWASHIMA* and Tatsuhiko KOYAMA**
}

\begin{abstract}
A series of dynamic loading tests with use of large-scale reinforced concrete bridge piers was conducted to investigate an effect of number of load reversals with the same displacement amplitude. The specimens were subjected to a series of step-wise increasing symmetric displacement with $n$ cycles, in which number of cycles $n$ was varied from 3 to 10 as a parameter to be investigated.

It was understood from the study that although deterioration of the specimen progresses, as a general trend, in accordance with increase of the number of inelastic loading cycles, for specimens which failed in flexure, effect of the number of loading cycles between 3 and 10 is less significant at the loading displacement smaller than or equal to the displacement at which the maximum load was developed.

Keywords : reinforced concrete pier, dynamic loading test, ductility, dynamic characteristics
\end{abstract}

\section{INTRODUCTION}

In the past, number of highway briges have suffered damages due to extreme earthquakes. Reinforced concrete bridge piers supporting superstructures are quite susceptible to damage from strong ground motions. This fact became evident during the Miyagi-ken-oki Earthquake of 1978, when numerous reinforced concrete bridge piers designed by the traditional elastic approach suffered severe damages ${ }^{1)}$. Such evidence clearly showed the importance to study inelastic behavior with energy dissipation of reinforced concrete bridge piers under severe ground motions.

Various investigations have been made to study inelastic behavior of reinforced concrete bridge piers subjected to strong earthquakes, and specimens simulating reinforced concrete bridge piers have been tested under various loading conditions such as static and dynamic cyclic loading, earthquake-like loading $^{2) ~-5)}$. In almost all the test, however, loads were step-wise increased monotonically up to failure, in which at each step several cycles of symmetrical loading reversals with the same displacement amplitude were carried out. Although number of loading cycles at each step may have a significant effect on the test results, little is known about the effect of load reversals on the mechanism of inelastic behavior of reinforced concrete bridge piers. Because structural response amplitude also highly depends on the number of response cycles ${ }^{6}$, it is inevitable to study such effects in order to apply the dynamic loading test data for practical seismic design of reinforced concrete bridge piers which are to be subjected to earthquake ground motion.

This study presents a series of dynamic loading test results of large-size reinforced concrete bridge pier

* Member of JSCE, Dr. Enger., Head of Earthquake Engineering Division, Earthquake Disaster Prevention Department, Public Works Research Institute, Ministry of Construction (Tsukuba Science City, Ibaraki-ken, Japan)

** Member of JSCE, Assistant Research Engineer, ditto. 
models subjected to different number of load reversals with the same displacement amplitude. Effect of number of loading cycles on strength and energy dissipating capacity either in flexure or shear was presented.

\section{TEST SPECIMENS AND EXPERIMENTAL SET-UP}

Seven large-size reinforced concrete specimens simulating cantilever piers of bridges as shown in Fig. 1 and Table 1 were used for the test. Specimen numbers presented show those used to identify specimens in a series of dynamic loading tests conducted at the Public Works Research Institute ${ }^{7)}$. The cantilever pier was framed into a massive reinforced concrete footing which was anchored to a test floor by means of post tensioned rods.

The common characteristics over the seven specimens are the cross section of $50 \mathrm{~cm} \times 50 \mathrm{~cm}$, main reinforcement ratio of $2.03 \%$ with use of $40 \mathrm{SD} 30$ bars (deformed bar) with diameter of $13 \mathrm{~mm}$, and tie reinforcement ratio of $0.1 \%$ with use of $9 \mathrm{~mm}$ diameter SR 24 bars (plain bar) placed at $25 \mathrm{~cm}$ intervals. The layout of tie bars depends on the Japanese practice in accordance with the Specifications for Design of Highway Bridges. The tie bars were lapped at least $60 \mathrm{~mm}$. They used portland cement with uni-axial compression strength ranging from 319 to $340 \mathrm{~kg} / \mathrm{cm}^{2}$, and aggregates with the maximum grain size of $10 \mathrm{~mm}$.

Effective pier heights $h$ from bottom to the center of loading point were taken as parameters to be investigated as $2.5 \mathrm{~m}(\mathrm{P}-10, \mathrm{P}-19$ and $\mathrm{P}-20), 1.752 \mathrm{~m}(\mathrm{P}-17$ and $\mathrm{P}-20)$ and $1 \mathrm{~m}(\mathrm{P}-18$ and $\mathrm{P}-20)$ so that the shear-span ratio, which is defined as a ratio between effective height $h$ and effective width $d$ (widthcovering depth), becomes $5.4,3.8$ and 2.2 , respectively.

Table 1 Specifications of Test Specimens.

\begin{tabular}{|c|c|c|c|c|c|c|c|c|}
\hline \multicolumn{2}{|c|}{ Shear-Span Ratio h/d } & \multicolumn{3}{|c|}{5.4} & \multicolumn{2}{|c|}{3.8} & \multicolumn{2}{|c|}{2.2} \\
\hline \multicolumn{2}{|c|}{ Number of Loading Cycles $n$} & 10 & 5 & 3 & 10 & 3 & 10 & 3 \\
\hline \multicolumn{2}{|l|}{ Specimen } & P-10 & $\mathrm{P}-22$ & P-19 & P-17 & $\mathrm{P}-20$ & $\mathrm{P}-18$ & $\mathrm{P}-21$ \\
\hline \multicolumn{2}{|l|}{ Cross-section } & $50 \times 50$ & $50 \times 50$ & $50 \times 50$ & $50 \times 50$ & $50 \times 50$ & $50 \times 50$ & $50 \times 50$ \\
\hline \multicolumn{2}{|c|}{ Effective Height $\mathrm{h}$} & 250 & 250 & 250 & 175 & 175 & 100 & 100 \\
\hline \multirow{2}{*}{$\begin{array}{l}\text { Main } \\
\text { Reinforcement }\end{array}$} & $\begin{array}{l}\text { Material and } \\
\text { Diameter }\end{array}$ & SD 30,13 & SD 30,13 & SD 30,13 & SD 30,13 & SD 30,13 & SD30,13 & SD 30,13 \\
\hline & $\begin{array}{l}\text { Reinforcement } \\
\text { Ratio }\end{array}$ & 2.03 & 2.03 & 2.03 & 2.03 & 2.03 & 2.03 & 2.03 \\
\hline \multirow{2}{*}{ Tie Bar } & $\begin{array}{l}\text { Material and } \\
\text { Diameter }\end{array}$ & SR24, 9 & SR 24, 9 & SR24, 9 & SR 24, 9 & SR24, 9 & SR24, 9 & SR 24,9 \\
\hline & $\begin{array}{l}\text { Reinforcement } \\
\text { Ratio }\end{array}$ & 0.1 & 0.1 & 0.1 & 0.1 & 0.1 & 0.1 & 0.1 \\
\hline \multirow{2}{*}{$\begin{array}{l}\text { Concrete } \\
\left(\begin{array}{l}\text { Portland } \\
\text { Cement }\end{array}\right)\end{array}$} & $\begin{array}{l}\text { Max. Grain Size } \\
\text { of Aggregate }\end{array}$ [mm] & 10 & 10 & 10 & 10 & 10 & 10 & 10 \\
\hline & $\begin{array}{l}\text { Cylinder } \\
\text { Strength } \quad\left[\mathrm{kgf} / \mathrm{cm}^{2}\right]\end{array}$ & 319 & 320 & 340 & 328 & 324 & 334 & 321 \\
\hline \multicolumn{2}{|l|}{ Loading Velocity } & 25 & 25 & 25 & 25 & 25 & 25 & 25 \\
\hline
\end{tabular}
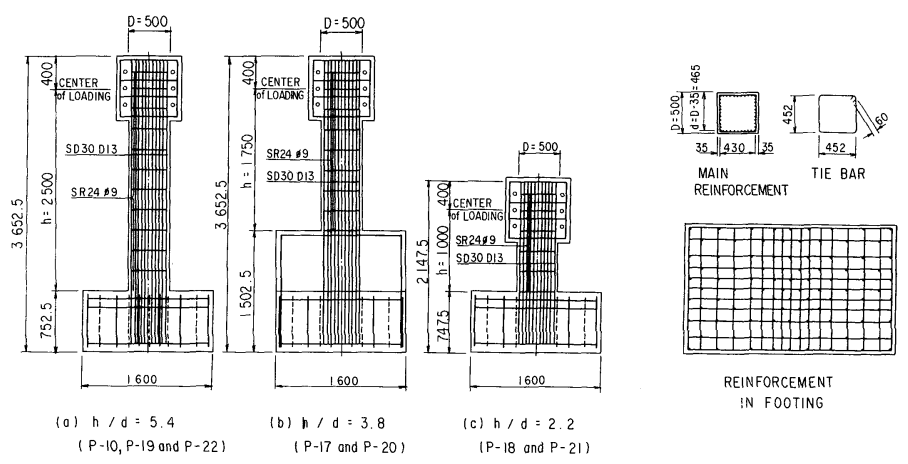

Fig. 1 Test Specimens. 


\section{LOADING CONDITIONS}

The specimens were loaded at the cantilever tip as shown in Fig. 2 by means of an electro-hydraulic dynamic actuator with loading capacity of $125 \mathrm{tf}$, max. stroke of $\pm 125 \mathrm{~mm}$ and max. loading velocity of $1 \mathrm{~m} / \mathrm{sec}$. Extensive electric instrumentation was used to measure and record the basic deformation parameters such as strains of main and tie reinforcements as well as the displacement and acceleration at the loading point. Although a compression stress of about 5 to $20 \mathrm{kgf} / \mathrm{cm}^{2}$ is generated in the piers with ordinary shape and height due to the dead weight of superstructure, it was disregarded in the test because of its limited effects.

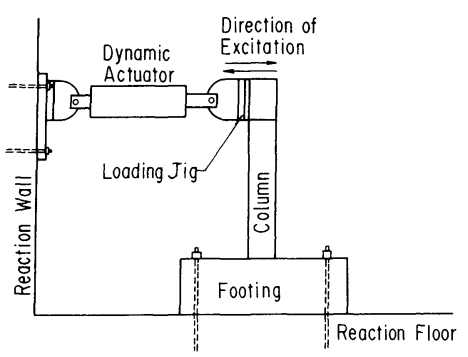

Fig. 2 Experimental Set-up.

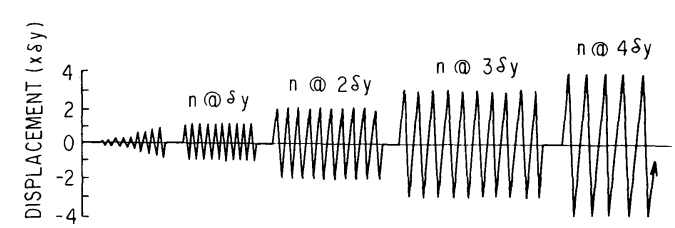

Fig. 3 Step-wise Increasing Symmetric Loading Displacement with $n$ Reversals.

The specimens were subjected to a series of step-wise increasing symmetric displacement cycles as shown in Fig. 3. At each step, $n$ cycles of loading with the same displacement amplitude was carried out, in which number of cycles $\mathrm{n}$ was varied from 3 to 10 as a parameter to be investigated. The step-size was determined by increasing the displacement in each step by a displacement ductility factor of one. The yield displacement $\delta_{y}$ corresponding to one ductility factor was defined as the displacement at loading point at which reinforcing bars at the extreme tension fiber firstly reached yield strain. A number of strain gauges were placed on the two longitudinal reinforcing bars on each side to the loading direction, and the averaged strain of the two reinforcing bars, which were detected at the foot of pier, was used to determine the yield displacement. The yield strain of reinforcement was assumed as $1800 \mu$ based on a number of tensile test of the specimens.

The loading velocity was taken as $25 \mathrm{~cm} / \mathrm{sec}$. over each step. Because the force detected by means of a load-cell equipped in the dynamic actuator represents total force applied to the specimen including an inertia force associated with masses of the specimen and the loading jig, the lateral force $P$ which actually loaded to the specimen was calculated assuming that the inertia force along the cantilever pier distributes in an inverted-triangle shape with the inertia force at the foot being zero.

It should he noted here that in specimen $\mathrm{P}-18$, slips between footing and test floor were developed during the $2 \delta_{y}$ loading due to inadequate anchoring of the specimen to the floor. Therefore, the $2 \delta_{y}$ loading was subsequently carried out again, and these data were treated as those for $2 \delta_{y}$ loading.

\section{EFFECT OF NUMBER OF LOADING CYCLES}

\section{(1) Failure mode}

Figs. 4, 5 and 6 show failure modes of the model piers with emphasis on cracks and spalling-off of cover concrete as well as elongation, buckling and cut of reinforcements. Failure modes on the side perpendicular and parallel to the loading direction are presented here for the specimens with shear-span ratio of 5.4 and 3. 8, and those with shear-span ratio of 2.2, respectively, so that progress of failure mode be clearly observed.

The specimens with shear-span ratio of 5.4 and 3.8 failed clearly in flexure. By increasing loading displacement, flexural cracks were firstly formed on the side near foot, and spalling-off of cover concrete 


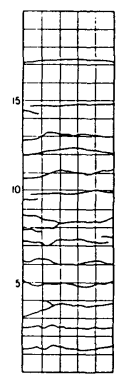

$\delta_{y}$

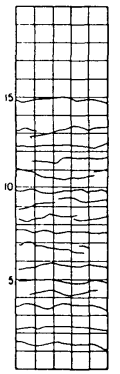

$\delta_{y}$

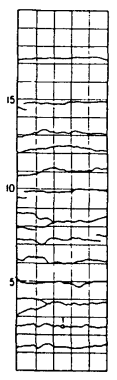

$2 \delta_{y}$

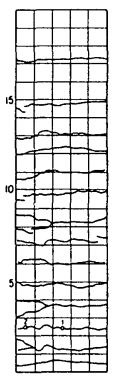

$3 \delta_{y}$

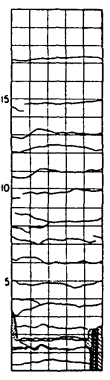

$4 \delta_{y}$

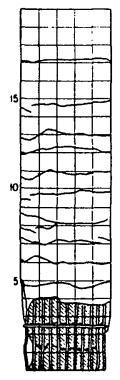

$5 \delta_{y}$

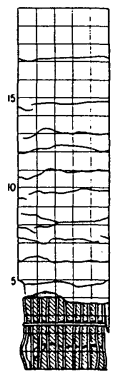

$6 \delta_{y}$

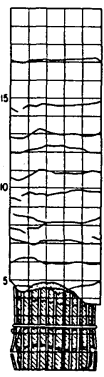

$7 \delta_{y}$

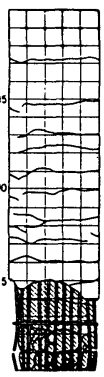

$8 \delta_{y}$

(a) Number of Loading Cycle $n=10$

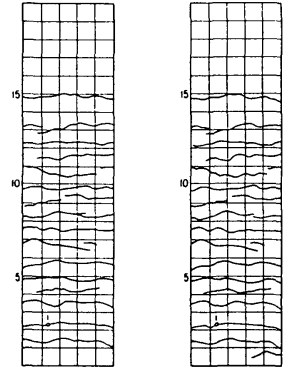

$3 \delta_{y}$

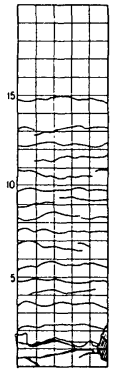

$4 \delta_{y}$

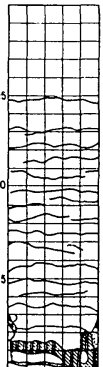

$5 \delta_{y}$

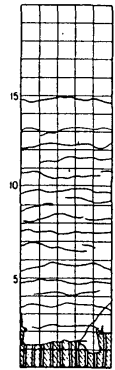

$6 \delta_{y}$

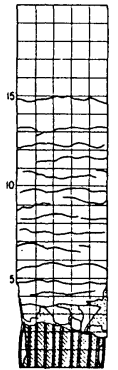

$7 \delta_{y}$

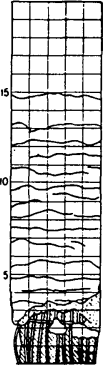

$8 \delta_{y}$

(b) Number of Loading Cycle $n=3$

Fig. 4 Failure Mode for Specimen with $h / d=5.4$

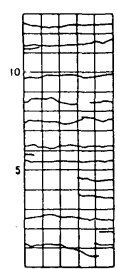

$\delta_{y}$

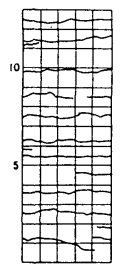

$2 \delta_{y}$

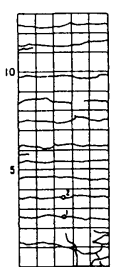

$3 \delta_{y}$

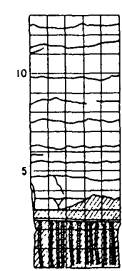

$4 \delta_{y}$

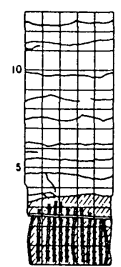

$5 \delta_{y}$

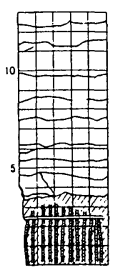

$6 \delta_{y}$

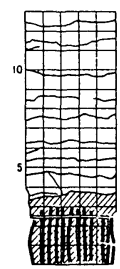

$7 \delta_{y}$

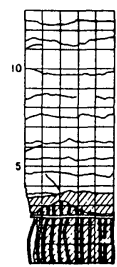

$8 \delta_{y}$

(a) Number of Loading Cycle $n=10$

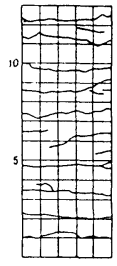

$\delta_{y}$

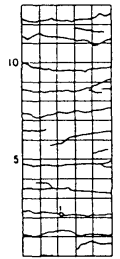

$2 \delta_{y}$

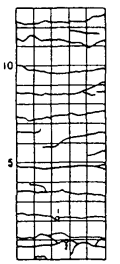

$3 \delta_{y}$

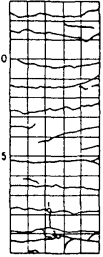

$4 \delta_{y}$

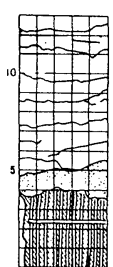

$5 \delta_{y}$

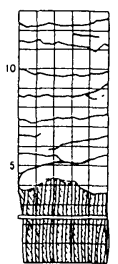

$6 \delta_{y}$

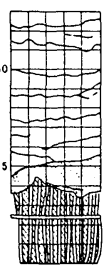

$7 \delta_{y}$

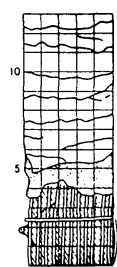

$8 \delta_{y}$

(b) Number of Loading Cycle $n=3$

Fig. 5 Failure Mode for Specimen with $h / d=3.8$

at the critical flexural region followed. Progress of significant flexural cracks finally penetrated the critical section causing break up of the concrete core, and inelastic buckling of main reinforcement either outwards between two adjacent tie bars or sideways were progressively developed. It should be noted here that pull-out of main reinforcement from footing was developed due to loss of bond caused by load reversals 


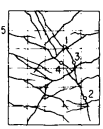

$\delta_{y}$

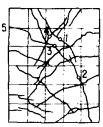

$\delta_{y}$

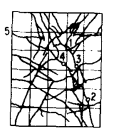

$2 \delta_{y}$

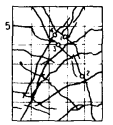

$2 \delta_{y}$

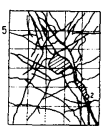

$3 \delta_{y}$

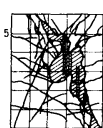

$4 \delta_{y}$

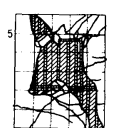

$5 \delta_{y}$

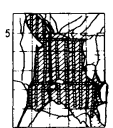

$6 \delta_{y}$

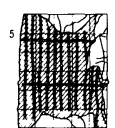

$7 \delta_{y}$

(a) Number of Loading cycle $n=10$

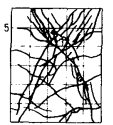

$3 \delta_{y}$

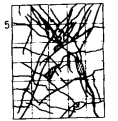

$4 \delta_{y}$

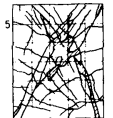

$5 \delta_{y}$

(b) Number of Loading Cycle $n=3$

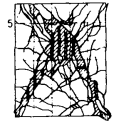

$6 \delta_{y}$

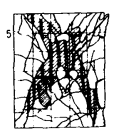

$7 \delta_{y}$

Fig. 6 Failure Mode for Specimen with $h / d=2.2$

in the anchorage, which, in turn, caused rotation at the foot and contributed to the pier displacement significantly. Eventually cut of main reinforcement was developed which critically deteriorated the load and stiffness.

In comparison, the specimens with shear-span ratio of 2.2 failed in shear. By increasing loading displacement, diagonal shear cracks were firstly developed on the side, and break up of the concrete core accompanying complete spalling-off of the cover concrete brings to final degradation of the stiffness.

In all the above-descibed failure modes, increase of the number of loading cycles $n$ clearly accelerates failure in accordance with increase of loading displacement. For example, the specimen with shear-span raio of 5.4, which were subjected to three reversals at each loading step, suffered spalling-off of cover concrete only at a region $30 \mathrm{~cm}$ from the foot even after the loading with displacement amplitude of $8 \delta_{y}$, while the same specimen subjected to ten reversals at each loading suffered much severe spalling-off of cover concrete at a region $40 \mathrm{~cm}$ from the foot after the $5 \delta_{y}$ loading.

Table 2 shows an effect of number of loading cycles for flexural failure in terms of number of longitudinal reinforcements which were cut due to cyclic inelastic buckling. No longitudinal reinforcements were cut in the specimens which failed in shear. It is apparent that the number of loading cycles is of significant factor affecting the ultimate failure mode of flexural cantilever piers associated with cut of main reinforcement.

Fig. 7 shows strains induced in the tie bars of the specimens with shear-span ratio of 2.2. Although failure of concrete made unable to measure the strain of tie bars for larger loading displacements, it is apparent that increase of number of loading cycles brings increase of strains developed in tie bars. It should be noted that tie bar at $50 \mathrm{~cm}$ from foot (mid-height of the pier), which were subjected to ten reversals at each step, already yielded even at $2 \delta_{y}$ loading displacement.

(2) Strength and deformation capacity

The behavior of the test specimens was firstly studied from continuous plots of hysteresis loop of the load vs. displacement at the loading point. Fig. 8 shows the hysteresis loops of the specimens subjected to

Table 2 Number of Longitudinal Reinforcement Cut During Cyclic Loading.

\begin{tabular}{|l|c|c|c|c|c|c|c|}
\hline Shear-Span Ratio $\mathrm{h} / \mathrm{d}$ & \multicolumn{3}{|c|}{5.4} & \multicolumn{3}{|c|}{3.8} & \multicolumn{3}{|c|}{2.2} \\
\hline Number of Loading Cycles $\mathrm{n}$ & 10 & 5 & 3 & 10 & 3 & 10 & 3 \\
\hline $1 \sim 5 \delta \mathrm{y}$ & 0 & 0 & 0 & 0 & 0 & 0 & 0 \\
\hline $6 \delta \mathrm{y}$ & 1 & 0 & 0 & 0 & 0 & 0 & 0 \\
\hline $7 \delta \mathrm{y}$ & $3(4)$ & 0 & 0 & 6 & 0 & 0 & 0 \\
\hline $8 \delta \mathrm{y}$ & $7(11)$ & 2 & 0 & $6(12)$ & 0 & 0 & 0 \\
\hline
\end{tabular}

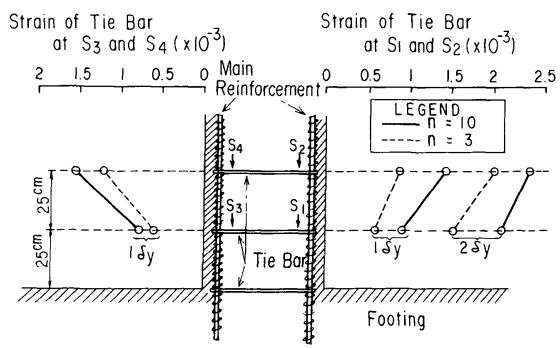

Fig. 7 Strains Induced in Tie Bars. 
loading with number of cycles of three and ten. Fig. 9 shows comparisons of the envelopes of the hysteresis loops.

For the flexural specimens with shearspan ratio of 5.4 and 3.8, effect of the number of loading cycles varies in accordance with loading displacement : For loading displacement smaller than or equal to $4 \delta_{y}$ for specimens with $h / d=5.4$ and $3 \delta_{y}$ for specimens with $h / d=3.8$, the envelopes of hysteresis loop seem almost independent of the number of loading cycles. It should be noted here that the critical displacments $4 \delta_{y}(h / d=5.4)$ and $3 \delta_{y}(h / d=3.8)$ correspond to those at which the maximum loads were achieved. This implies that for flexural specimens the number of loading cycles has less significant effect on the envelopes of hysteresis loop until the maximum load is developed. However after these displacements, a significant drop in load can be observed in the envelopes in accordance with increase of the number of loading cycles. Especially, as was previously discussed, drops in load associated with cut of longitudinal reinforcements critically depend on the number of loading cycles.

On the other hand, for the specimens with shear-span ratio of 2.2 , which failed in shear, more significant changes of envelope of hysteresis loop in accordance with the number of loading cycles are observed, i. e., for loading displacement larger than $\delta_{y} \sim 2 \delta_{y}$, the envelope of the specimen subjected to ten reversals is
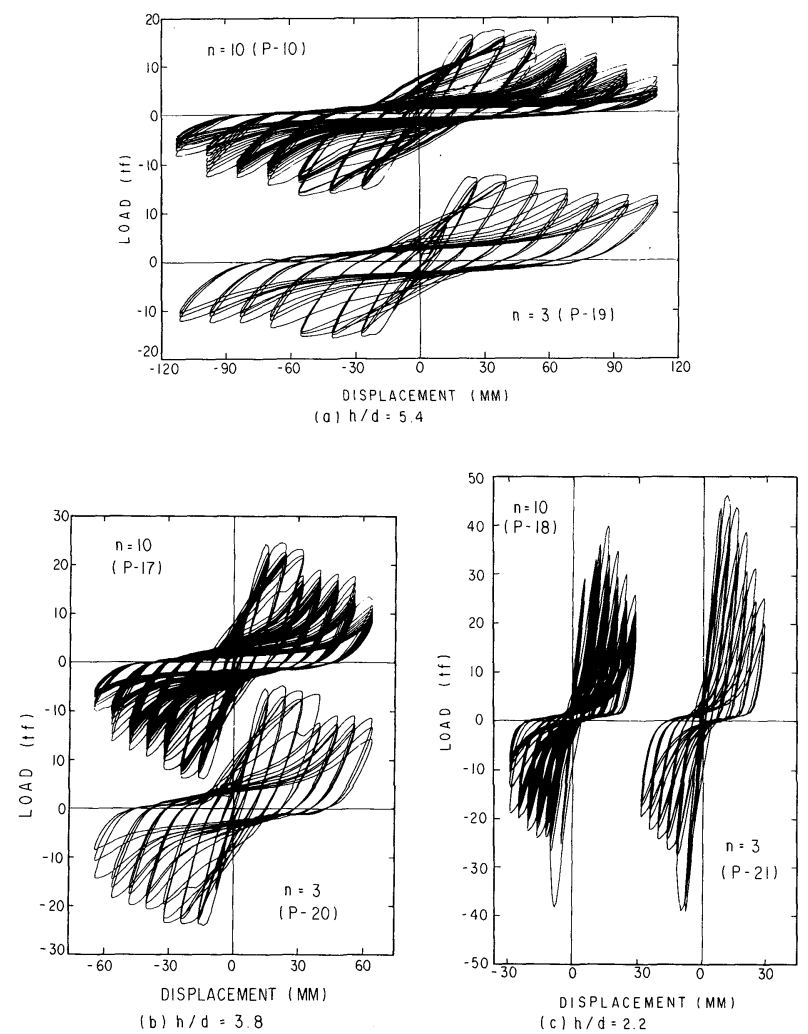

Fig. 8 Comparison of Hysteresis Loops.

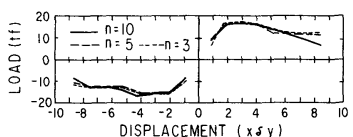
(0) $\mathrm{h} / \mathrm{d}=5.4$
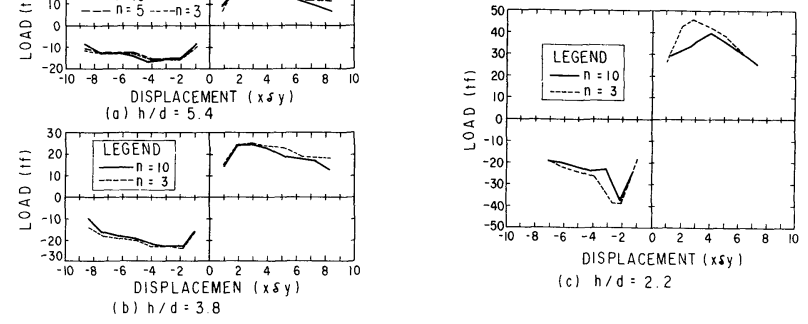

Fig. 9 Comparison of Envelope of Hysteresis Loops.

much smaller in load than that of the specimen subjected to three reversals. It should be, however, noted that there is some doubts as to whether the difference observed in the comparison of envelops can be entirely attributed to the effect of number of loading cycle, because of the slips developed in specimen $\mathrm{P}-18$ between footing and test floor during $2 \delta_{y}$ loading. As was described in the preceding chapter, as a consequence the $\mathrm{P}-18$ specimen was totally subjected to 20 load reversals with $2 \delta_{y}$ displacement, and this might cause appreciable deterioration of the specimen. However, since progress of break up of the concrete core accompanying yielding of tie bars is pronounced in shear specimens, it is considered reasonable that effect of number of loading cycle is more pronounced in shear specimens than in flexural specimens although the difference observed in Fig. 9 (c) is not necessarily entirely caused by the effect of number of loading cycles.

Table 3 summalizes the yield load $P_{y}$, max. load $P_{u}$, yield displacement $\delta_{y}$ and ultimate displacement $\delta_{u}$ 
Table 3 Comparison of Load and Displacement Performance.

\begin{tabular}{|c|c|c|c|c|c|c|c|c|}
\hline \multicolumn{2}{|c|}{ Shear-Span Ratio $\mathrm{h} / \mathrm{d}$} & \multicolumn{3}{|c|}{5.4} & \multicolumn{2}{|c|}{3.8} & \multicolumn{2}{|c|}{2.2} \\
\hline \multicolumn{2}{|c|}{ Number of Loading Cycles $n$} & 10 & 5 & 3 & 10 & 3 & 10 & 3 \\
\hline \multirow{3}{*}{ Load } & Yield Load Py $\quad[t f]$ & 11.6 & 10.9 & 10.9 & 15.9 & 15.5 & 27.6 & 27.7 \\
\hline & Maximum Load Pu [tf] & 16.8 & 16.7 & 16.6 & 24.2 & 24.6 & 39.1 & 42.7 \\
\hline & $\mathrm{Pu} / \mathrm{Py}$ & 1.45 & 1.53 & 1.52 & 1.52 & 1.59 & 1.42 & 1.54 \\
\hline \multirow{3}{*}{ Displacement } & $\begin{array}{l}\text { Yield Displace- } \\
\text { ment } \delta \mathrm{y}\end{array}$ & 1.30 & 1.30 & 1.30 & 0.75 & 0.75 & 0.39 & 0.39 \\
\hline & $\begin{array}{l}\text { Ultimate Displace- } \\
\text { ment } \delta \mathrm{cm}]\end{array}$ & 9.26 & 11.45 & 12.59 & 5.92 & 7.08 & 2.02 & 1.99 \\
\hline & $\delta \mathrm{u} / \delta \mathrm{y}$ & 7.1 & 8.8 & 9.7 & 7.9 & 9.4 & 5.2 & 5.10 \\
\hline
\end{tabular}

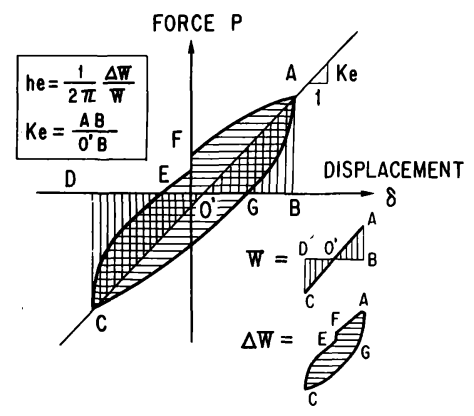

Fig. 10 Definition of Equivalent Hysteretic Damping Ratio.

for seven specimens. Only averaged values developed between in positive and in negative loading directions are presented in Table 3. For specimens with shear-span ratio of 5.4 and 3. 8, the max load $P_{\max }$ is almost free from the number of loading cycles, which, in turn, shows that a ratio of the max. load to the yield load, $P_{u} / P_{y}$, is also almost independent of the number of loading cycles. For specimens with shear-span ratio of 2.2 , the max. load $P_{u}$ when subjected to three inelastic reversals is only $8 \%$ larger than that subjected to ten inelastic reversals, i. e., effect of number of loading cycles in terms of the max. load $P_{u}$ is not necessarily significant as anticipated from clear difference which was observed in the envelope of hysteresis loop presented in Fig. 9 (c).

In comparison, the ultimate displacement $\delta_{u}$ of the specimens which failed in flexure significantly varies in accordance with the number of loading cycles, which, in turn, affects the ductility factors, i. e., a ductility factor obtained from the tests using three inelastic reversals for the same displacement amplitude is $36 \%$ and $19 \%$ larger than those from ten inelastic reversals tests for specimens with shear-span ratio of 5.4 and 3.8, respectively. Therefore the number of loading cycles have to be well examined when the ductility factors obtained with different test procedures are to be compared. The ductility factor for specimens with shear-span ratio of 2.2 does not, however, show significant changes with respect to the number of loading cycles.

\section{( 3 ) Energy dissipating capability}

An area surrounded by a hystersis loop as shown in Fig. 10 represents an amount of energy dissipated during that loading reversal, and hence, accumulating the energy dissipation during each loading reversal, total amount of energy dissipated in the specimen during the loading test may be calculated. Since the accumulated energy dissipation so obtained is lager in those specimens which experienced larger number of loading cycles, direct comparisons of the accumulated energy dissipation do not represent the energy dissipation capability of the specimens. Therefore, the accumulated energy dissipation calculated for the specimens which were subjected to three and five cycles of inelastic reversals for each loading step were multiplied by a factor of $10 / 3$ and $10 / 5$, respectively, so that the accumulated energy dissipation be compared on the basis of the same number of loading cycles of ten. Fig. 11 represents the accumulated energy dissipation thus obtained.

As anticipated from the previous discussions, the accumulated energy dissipation significantly decreases with increasing the number of loading cycles not only in the specimens which failed in flexure but those in shear. It should be noted, however, that such decreases of the accumulated energy dissipation with respect to increase of the number of loading cycles become apparent at the loading displacement larger than about $4 \delta_{y}, 3 \delta_{y}$ and $2 \delta_{y}$ for the specimens with shear-span ratio of $5.4,3.8$ and 2.2 , respectively. It should be reminded from Fig. 9 that those loading displacements almost correspond to the loading displacement at which the maximum load was developed. Therefore it may be considered that effects of the number of loading cycles on capability of energy dissipation are less significant until the maximum load was 

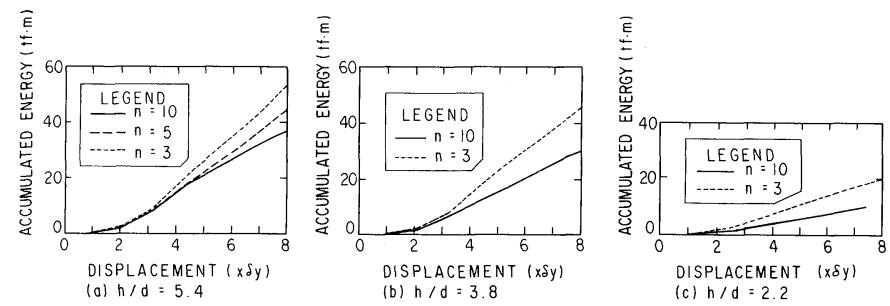

Fig. 11 Comparison of Accumulated Energy Dissipation.
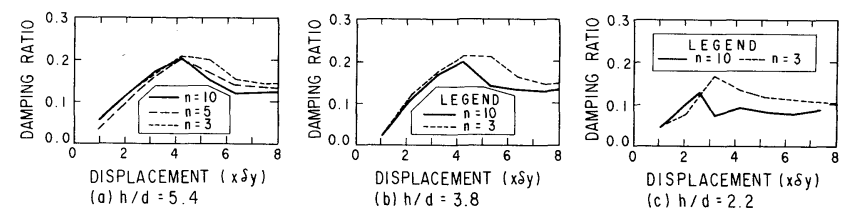

Fig. 12 Comparison of Equivalent Hysteretic Damping Ratio.

developed, and that it progressively becomes significant after the maximum load. Total amount of accumulated energy dissipated during the test for the specimens which were subjected to three load reversals is approximately $50 \%$ larger than that for the specimens which were subjected to ten load reversals.

Energy dissipation capability was also studied in terms of an equivalent hysteretic damping ratio $h_{e}$ which is defined as

$$
h_{e}=\frac{1}{2 \pi} \frac{\Delta W}{W}
$$

in which $\Delta W$ is an energy dissipated during one load reversal and $W$ is an elastic energy as defined in Fig. 10.

Fig. 12 shows variations of the equivalent hysteretic damping ratio $h_{e}$ with respect to the displacement amplitude of cyclic loading. As a general trend, the equivalent damping ratios increase with increasing the loading displacement, take a peak value of approximately 0.2 at $4 \delta_{y}(h / d=5.4$ and 3.8) and $0.12 \sim 0.16$ at $2 \sim 3 \delta_{y}(h / d=2.2)$, and progressively decrease to a value of about $0.15(h / d=5.4$ and 3.8) and 0.1 $(h / d=2.2)$. The effect of number of loading cycles can be observed in the decreasing path after $h_{e}$ takes the peak value, i. e., $h_{e}$ decreases promptly in the specimens which were subjected to larger number of loading cycles.

\section{CONCLUDING REMARKS}

In an attempt to study effects of number of inelastic loading cycles on strength and energy dissipating characteristics of reinforced concrete bridge piers, a series of dynamic loading tests with use of seven large-size specimens was conducted by varying the number of inelastic loading cycles from three to ten. Based on the test results presented, the following conclusions may be deduced:

(1) As a general trend, deterioration of the specimen progresses in accordance with increase of the number of inelastic loading cycles with regardless of flexural failure or shear failure.

(2) However, for specimens with shear-span ratio of 5.4 and 3.4 which failed in flexure, effect of the number of loading cycles between 3 and 10 is less significant for the loading displacement smaller than or equal to the displacement at which the maximum load was developed. Within this loading displacement, the envelope of hysteresis loop, accumulated energy dissipation, equivalent hysteretic damping ratio and the maximum load are less significantly affected by the number of inelastic loading cycles. However, over this displacement, deteriorations of the specimen becomes significant in accordance with number of inelastic 
loading cycles. Especially, deterioration of the specimen associated with cut of main reinforcement due to cyclic inelastic buckling critically depends on the number of loading cycles.

(3) For the specimens with shear-span ratio of 2.2, which failed in shear, the effect of number of inelastic loading is much significant as compared with the flexural specimens. The envelope of hysteresis loop shows significant drop in load at displacements larger than $\delta_{y} \sim 2 \delta_{y}$.

\section{REFERENCES}

1) Okubo, T., Ohashi, M., Iwasaki, T., Kawashima, K. and Tokida, K. : Damage Features of Civil Engineering Structures due to The Miyagi-ken-oki Earthquake of 1978, 11th Joint Meeting, Wind and Seismic Effect, UJNR, Tsukuba, Japan, 1979.

2) Park, R. and Blakeley, R. W. G. : Seismic Design of Bridges, RRU Bulletin 43, National Roads Board, 1979.

3) Yamamoto, T., Ishibashi, T., Otsubo, M. and Kobayashi, S. : Experimental studies on Seismic Resistance of A Pier with Reinforcement Terminated in A Tension Zone, Proc. of JSCE, Vol. 348, V-1, 1984.

4) Ohta. M. : A Study on Earthquake Resistant Design for Reinforced Concrete Bridge Piers of Single-Column Type, Report of the Public Works Research Institute, Vol. 153, 1980 (in Japanese).

5) Ikeda, S., Eya, S. and Yamaguchi, T. : Behavior of Reinforced Concrete Cylindrical Columns under Reversed Cyclic Loadings, Trans. of the Japan Concrete Institute, 1986.

6) Kawashima, K. and Aizawa, K. : Earthquake Response Spectra Taking Account of Number of Response Cycles, Earthquake Engineering and Structural Dynamics, Vol. 14, 1986.

7) Kawashima, K., Hasegawa, K., Koyama, T. and Yoshida, T. : Experimental Investigation on Dynamic Strength and Ductility of Reinforced Concrete Bridge Piers, Part I, No. 2232 of the Technical Memorandum, Public Works Research Institute, Ministry of Construction, 1985.

(Received March 9 1987) 